\title{
Yüksek Dereceli Servikal İntraepitelyal Lezyonların Tedavisinde Leep ile Soğuk Konizasyon Tekniklerinin Karşılaştırılması
}

\author{
Comparison of the Cold-Knife Conization and Leep in the Treatment of \\ Cervical High Grade Intraepthelial Lesions
}

\section{Taner GÜNAY ${ }^{1}$, Mesut POLAT ${ }^{1}$, Oğuz Devrim YARDIMCI ${ }^{1}$, Meryem HOCAOĞLU ${ }^{1}$ Ergül Demirçivi BÖR ${ }^{1}$, Rabia Burçin GİRGİN ${ }^{2}$, Abdulkadir TURGUT ${ }^{3}$}

1. Medeniyet Üniversitesi, Göztepe Eğitim ve Arș. Hastanesi, Kadın Hastalıkları ve Doğum Ana Bilim Dalı, İstanbul, Türkiye

2. Medeniyet Üniversitesi Göztepe Eğitim ve Araştırma Hastanesi, Patoloji Ana Bilim Dall, İstanbul, Türkiye

3. Medeniyet Üniversitesi Tip Fakültesi, Kadın Hastalıkları ve Doğum Ana Bilim Dalı, İstanbul, Türkiye

\section{$\ddot{O Z Z E T}$}

Amaç: Yüksek dereceli servikal intraepiteliyal neoplazilerin tedavisinde yaygin olarak kullanılan LEEP ile soğuk konizasyon tekniklerinin etkinlik, başarl ve postoperatif erken dönem sonuçlarını karșılaștırmak.

Gereçler ve Yöntem: Medeniyet Üniversitesi Göztepe Ĕ̈itim ve Araştırma Hastanesi Kadın Hastalıklarl ve Doğum Kliniğinde Eylül 2015 ile Ocak 2019 tarihleri arasinda servikal biyopsi sonucu yüksek dereceli intraepiteliyal neoplazi (CIN 2, CIN 3) olarak gelen ve bu nedenle LEEP veya soğuk konizasyon yapılan hastaların verileri retrospektif olarak değerlendirildi. Yüksek dereceli intraepitelyal neoplazi tanısı ile LEEP yapılan 87 hasta ile soğuk konizasyon (cold-knife) yapılan 48 hastanın demografik verileri, preoperatif sitoloji ve biyopsi sonuçlart, operasyon süreleri, spesimenin patolojik özellikleri ve erken dönem komplikasyonları karşılaş̧ırıldı.

Bulgular: LEEP yapılan 87 hastada ortalama yaş $46.28 \pm 6.05$ iken soğuk konizasyon yapılan 48 hastada $47.92 \pm 5.99$ idi ve anlaml fark bulunmadr. Bununla birlikte soğuk konizasyon grubunda hastalarin gravida ve paritesi istatistik olarak anlamlı olacak şekilde yüksek bulundu $(p<0.05)$. LEEP tekniğinde operayon süresi soğuk konizasyona göre daha kısa bulundu $(p<0.05)$. Çıkarılan spesimeninin derinliği ve genişliği soğuk konizasyon grubunda LEEP grubuna göre daha büyük saptan$d_{l}(p<0.05)$. Cerrahi sinır pozitifliği ile, kanama ve enfeksiyon gibi erken postoperatif komplikasyonlar bakımından gruplar arasinda fark saptanmadı $(p>0.05)$.

Sonuç: Tedavi başarısı olarak cerrahi sinırlarda lezyon izlenmemesi alındiğında yüksek dereceli servikal intraepitelyal neoplazilerin tedavisi için yapılan LEEP ve soğuk konizasyon tekniğinin başarl ve etkinliği benzer bulundu. Erken dönem komplikasyonlart da benzer olmakla birlikte LEEP tekniğinde soğuk konizasyona göre operasyon süresi daha klsa bulundu. Soğuk konizasyon tekniğinin ise termal hasara yol açmamast ve histopatolojik değerlendirme için LEEP'e göre daha fazla miktarda doku sağlanabilmesi avantajlı olduğu yönleridir.

Anahtar Kelimeler: servikal intraepitelyal neoplazi, LEEP, soguk konizasyon

\section{İletișim}

Sorumlu Yazar: Taner GÜNAY

Adres: Medeniyet Ünv., Göztepe Eğt. ve Arș. Hastanesi, Kadın Hast. ve Doğ. Kliniği, Eğitim Mah. Dr. Erkin Cd. Kadıköy/İstanbul 34722, Türkiye Tel: +90 (216) 5666600

E-Posta: tanergunay@hotmail.com

Makale Geliș: 21.03.2019

Makale Kabul: 22.11.2019

DOI: http://dx.doi.org/10.16948/zktipb.542674

\begin{abstract}
Objective: To compare the efficiency, success and early postoperative results of cold-knife conization and loop electrosurgical excision procedure (LEEP) commonly performed in the treatment of cervical high grade intraepithelial lesions (HSIL).
\end{abstract}

Material and Methods: The data of the patients with high grade intraepithelial neoplasia (CIN2, CIN3) cervical biopsy results who underwent cold-knife conization or LEEP between January 2015 and January 2019 in Göztepe Training and Research Hospital, affliated with Medeniyet University, were evaluated retrospectively. The demographic characteristics, initial sitology and cervical biopsy results, lenght of operation times, and pathologic examination results of specimens and early postoperative complications of 87 patiens who underwent LEEP and 48 patient with cold-knife conization were compared.

Results: The mean age was $46.28 \pm 6.05$ in 87 patients who underwent LEEP and $48.92 \pm 5.99$ in 48 patients who had cold conization and has not a statitistical significance. In cold-knife conization group, parity and gravida were higher with a statistical significance $(p<0.05)$. Operation time was found to be shorter in LEEP group than conization group $(p<0.05)$. The depth and width of the surgical specimens were found to be higher in cold-knife group than LEEP group $(p<0.05)$. In terms of the positivity of disease in surgical borders and postoperative complication such as amount of bleeding and infection rates there were no statistically significance $(p>0.05)$.

Conclusion: Regarding the absence of the disease at the surgical margins the success of cold-knife conization and LEEP techniques was found to be similar. Early surgical complication rates were similar in two group. Supplying large specimens and non creating thermal injury are the major advantages of performing cold-knife conization method.

Keywords: cervical intraepithelial neoplasia, cold-knife conization, LEEP

\section{GíRiș}

Servikal intraepitelyal neoplazi (Cervical Intraepithelial Neoplasia-CIN), serviks çok katlı yass1 epitelini oluşturan hücrelerin atipik bir karakter kazanması ile ortaya çıkan epitel bozukluğuna verilen isimdir. Anormal lezyonlar epitelin alt 1/3'ünde sinırlı ise CIN I, alt 2/3'ünde ise CIN II, epitelin tamamına yakını atake olmuşsa CIN III, tamamını içeriyorsa karsinoma in-situ (CIS) olarak adlandırılır. CIN I düşük dereceli lezyon olarak kabul edilirken CIN II ve III yüksek dereceli lezyonlar olarak değerlendirilir. 
CIN lezyonlarının en belirgin özelliği hücre bozukluğunun serviksin çok katlı yassı epitelinde sinırl olması ve stroma ile epitel katmanını birbirinden ayıran bazal membranın aşılmamış olmasıdır (1). CIN II ve CIN III, içinde karsinoma in situ olgularının da bulunduğu prekanseröz lezyon grubudur. $\mathrm{Bu}$ olgular bazı özel durumlar dışında tedavi edilmesi gereken olgulardır. Bununla beraber CIN II olgularını biyolojik davranışları dolayısıyla CIN III olgulardan ayırdetmek yerinde olur. CIN II lezyon grubu daha heterojen bir gruptur. Takip esnasinda CIN III lezyonlara göre daha yüksek oranda gerileme gösterme eğilimindedirler. Fakat bu iki grubu histolojik olarak kesin sınırlar ile ayırdetmek kolay değildir. Bu nedenle öneriler her iki lezyon grubunu ilgilendiren önerilerdir (2).

Skuamöz intraepitelial neoplazilerde tedavinin amacı transformasyon zonunu eradike etmektir. Üç temel eksizyon metodu vardır; 'cold-knife' kon biyopsi, lazer eksizyon ve transformasyon zonunun geniş loop eksizyonu (LLETZ). Son bahsedilen teknik olan LLETZ, ABD ve diğer ülkelerde loop elektrocerrahi eksizyon prosedür (LEEP) olarak bilinmekte olup kesme/yakma fonksiyonları olan bir elektrokoter sistemidir (3). Bistüri veya 'cold-knife' kon biyopsi de geleneksel yöntem olarak Avrupa'da birçok ülkede yaygin olarak kullanılmaktadır. Eksizyon sinırlarında artefakt hasarı yapmamasından dolayı glandüler ve mikroinvaziv hastalığın tedavisinde oldukça yaygin olarak tercih edilmektedir. Metod genel anestezi ve ameliyathane ortamı gerektirmektedir. Geleneksel olarak uygulama sonras1 yara iyileşmesi yeni skuamokolumnar bileşkenin içeri doğru çevrilmesi Sturmdorf sütürleri ile yapılmaktadır. Bununla beraber artmış servikal morfolojik hasar, takip eden stenoz kaynaklı dismenore ve servikal yetmezliğe sekonder olarak gelişen prematür doğum riski vardır (4). Her iki teknik de gerçek tanının konabileceği daha kapsamlı bir histolojik değerlendirme sağlar, eksizyon sınırlar1 daha iyi saptanır ve mikroinvazyon veya glandüler hastalık saptanabilir veya ekarte edilir. $\mathrm{Bu}$ çalışmanın amacı yüksek dereceli servikal intraepiteliyal neoplazilerin tedavisinde yaygin olarak kullanılan LEEP ile soğuk konizasyon tekniklerinin etkinlik, başarı ve postoperatif erken dönem sonuçlarının karşılaştırılmasıdır.

\section{GEREÇ ve YÖNTEM}

$\mathrm{Bu}$ retrospektif çalışmada İstanbul Medeniyet Üniversitesi Göztepe Eğitim ve Araştırma Hastanesi Kadın Hastalıkları ve Doğum Kliniğinde Eylül 2015 ile Ocak 2019 tarihleri arasinda servikal biyopsi sonucu yüksek dereceli intraepiteliyal neoplazi (CIN 2, CIN 3) olarak gelen ve bu nedenle LEEP veya soğuk konizasyon yapılan hastaların verileri değerlendirildi. Çalışma için etik kurul onayı alındı. Yüksek dereceli intraepitelyal neoplazi tanısı ile LEEP yapılan 87 hasta ile soğuk konizasyon (cold-knife) yapılan 48 hastanın demografik verileri, preoperatif sitoloji ve biyopsi sonuçları, operasyon süreleri, spesimenin patolojik özellikleri ve erken dönem komplikasyonları açısından karşılaştırıldı.
Tüm hastalara LEEP veya soğuk konizasyon öncesinde kolposkopik biyopsi ve endoservikal küretaj yapıld1. LEEP ve soğuk konizasyon işlemi ameliyathane şartlarında ve genel anestezi altında yapıldı. Hastalara yapılan tüm işlemler için onam alındı. İşlem öncesinde servikse $\% 5^{\prime}$ lik asetik asit ve/veya lügol solüsyonu uygulandi. LEEP işlemi Covidien ForceTriad cihazı ve Valleylab Tungsten Loop Electrode kullanilarak cut (kesme) ve koagülasyon modu 40-50 watt olacak şekilde yapildı. LEEP veya soğuk konizasyon işlemi sırasında gerekli durumlarda hemostaz koterizasyon, sütürasyon veya monsel's solüsyonu ile sağlandı. Eksizyon materyali saat 12 hizasında işaretlenerek \%10'luk formol solüsyonu içinde patoloji laboratuarına gönderildi. Hastalar işlem sonrası 12-24 saat gözlem altında tutuldu. Gözlem sirasında vajinal kanama nedeniyle ek müdahale ihtiyacı ortaya çıkan hastalar ile postoperatif ilk ayda pelvik inflamataur hastalık semptom ve/veya bulguları ile başvuran ve klinik ve laboratuar bulguları ile pelvik enfeksiyonu düşündüren hastalar ile alınan kültür sonucunda üreme izlenen hastalar kaydedildi.

\section{İstatistiksel Analiz}

Değişkenlerin analizinde SPSS 25.0 (IBM Corparation, Armonk, New York, United States) programı kullanıldı. Verilerin normal dağılıma uygunluğu Shapiro-Wilk testi ile varyans homojenliği Levene ile değerlendirildi. Bağımsız iki grubun nicel verilere göre birbiri ile karşılaştırılmasında Independent-Samples T testi Bootstrap sonuçlarıyla birlikte kullanılırken Mann-Whitney U testi Monte Carlo sonuçlarıyla birlikte kullanıldı. Kategorik değişkenlerin birbiri ile karşılaştırılmasında ise Pearson Chi-Square ve Fisher Exact testleri Exact sonuçları kullanılarak test edilirken Fisher-Freeman-Holton testi Monte Carlo Simülasyon tekniği sonuçlarına göre ile test edildi. Nicel değişkenler tablolarda ortalama $\pm \mathrm{SS}($ Standart Sapma $)$ - (Minimum / Maximum) ve medyan (Minimum / Maximum) şeklinde gösterilirken kategorik değişkenler ise $\mathrm{n}(\%)$ olarak gösterildi. Değişkenler $\% 95$ güven düzeyinde incelenmiş olup p değeri 0,05 ten küçük anlamlı kabul edildi.

\section{BULGULAR}

Yüksek dereceli intraepitelyal neoplazi tanısı ile Eylül 2015 ile Ocak 2019 arasinda LEEP yapılan 87 hasta ile soğuk konizasyon (cold-knife) yapılan 48 hastanın demografik verileri ile preoperatif sitoloji ve patoloji sonuçları Tablo 1'de görülmektedir. Gruplar arasında yaş, preoperatif sitoloji le preoperatif biyopsi bulguları açısından fark saptanmadı. Bununla beraber soğuk konizasyon yapılan hastalarda gravida ve paritesi LEEP grubundaki hastalara oranla daha yüksek bulundu $(\mathrm{p}<0.05)$.

LEEP grubunda preoperatif biyopsi sonucu CIN 2 olan 54 hastanın postoperatif patoloji sonucunda; 34 (\%63.0) hastada CIN 2, 10 (\%18.5) hastada daha yüksek dereceli (CIN 3 veya kanser) bir hastalık ve yine $10(\% 18.5)$ hastada daha düşük dereceli (CIN 1 veya hastalık yok) bir hastalık bulundu. Aynı grupta preoperatif biyopsi sonucu CIN 
3 olan 33 hastanın postoperatif patoloji sonucunda ise; $18(\% 54.4)$ hastada CIN 3, 5 (\%15.2) hastada daha yüksek dereceli (karsinoma insitu veya servikal kanser) hastalık ve $10(\% 30.4)$ hastada ise daha düşük dereceli (CIN 2, CIN 1 veya hastalık yok) bir hastalık bulundu.

Soğuk konizasyon grubunda preoperatif biyopsi sonucu CIN 2 olan 28 hastanın postoperatif patoloji sonucunda; 19 (\%67.8) hastada CIN 2, 4 (\%14.3) hastada daha yüksek dereceli (CIN 3 veya kanser) bir hastalık ve $5(\% 17.9)$ hastada ise daha düşük dereceli bir (CIN 1 veya CIN 2) hastalık bulundu. Aynı grupta preoperatif biyopsi sonucu CIN 3 olan 20 hastanın postoperatif patoloji sonucunda; $12(\% 60)$ hastada CIN 3, $2(\% 10)$ hastada daha yüksek dereceli (karsinoma insitu veya servikal kanser) hastalık ve $6(\% 30)$ hastada ise daha düşük dereceli (CIN 2, CIN 1 veya hastalık yok) bir hastalık bulundu. LEEP veya soğuk konizasyon yapılan hastalarında operasyon süreleri, çıkarılan spesimenin genişlik ve derinliği ile erken postoperatif dönemde ortaya çıkan komplikasyonlar Tablo 2'de görülmektedir. LEEP tekniğinde operayon süresi soğuk konizasyona göre daha kısa bulundu $(p<0.05)$. Çıkarılan spesimeninin derinliği ve genişliği soğuk konizasyon grubunda LEEP grubuna göre daha büyük saptand1 $(\mathrm{p}<0.05)$. Cerrahi s1nır pozitifliği ile, kanama ve enfeksiyon gibi erken postoperatif komplikasyonlar bakımından gruplar arasında fark saptanmadı $(\mathrm{p}>0.05)$.
Her iki gruptaki hastalarda postoperatif nihai patoloji sonuçları Tablo 3'de görülmektedir. Preoperatif yüksek dereceli CIN tanısı alan hastaların sonuçları postoperatif nihai patoloji sonuçları ile karşılaştırıldığında her iki tekniğin de benzer doğruluk oranlarına sahip olduğu bulundu $(\mathrm{p}>0.05)$.

\section{TARTIȘMA}

Yüksek dereceli servikal intraepitelyal neoplazilerin tedavisinde kullanılan soğuk konizasyon ile LEEP tekniğini karşılaştırdığımız çalışmamızda tedavi başarısı ve erken dönem komplikasyon oranları açısından benzer sonuçlar bulduk. Konizasyon işleminde tedavi başarısı olarak değerlendirilen en önemli parametre cerrahi sinırda (marjin) lezyon bulunmamasıdır. LEEP işleminde içinden elektrik geçirilen ince lup şeklinde bir telin serviksten hızlı bir şekilde geçirilmesi sonucunda doku elde edildiği için termal hasar son derece minimaldir ancak telin doku ile temas süresi arttıkça dokuda termal koagülasyon hasarı artmaktadır. Bu durum cerrahi sınırların net olarak değerlendirilememesine yol açar. Biz de çalışmamızda LEEP yaptığımız 6 (\%6.9) hastamızda yaygın koter artefaktı ile karşılaştık. Soğuk konizasyon yapılan hastalarda ise böyle bir risk yoktur. Bununla birlikte cerrahi sinırda hastalık olmaması her zaman nüks hastalığın olmayacağını garanti ettirmez.

Tablo 1: Hastaların demografik özellikleri ile preoperatif sitoloji ve patoloji sonuçları.

\begin{tabular}{|c|c|c|c|c|c|}
\hline & & Total & Leep & Soğuk Konizasyon & D \\
\hline & & $(\mathrm{N}=135)$ & $(n=87)$ & $(n=48)$ & $\mathbf{P}$ \\
\hline & & $\operatorname{Mean} \pm$ SD. - (Min. / Max.) & $\operatorname{Mean} \pm$ SD. - (Min. / Max.) & Mean \pm SD. - (Min. / Max.) & \\
\hline Yaş & & $46.86 \pm 6.06-(29 / 62)$ & $46.28 \pm 6.05-(29 / 62)$ & $47.92 \pm 5.99-(33 / 60)$ & $0.149^{1}$ \\
\hline & & Median (Min. / Max.) & Median (Min. / Max.) & Median (Min. / Max.) & \\
\hline Gravida & & $4(1 / 9)$ & $4(1 / 8)$ & $5(1 / 9)$ & $0.022^{2}$ \\
\hline Parite & & $2(1 / 6)$ & $2(1 / 6)$ & $3(1 / 5)$ & $0.029^{2}$ \\
\hline Preoper & atif sitolo & & & & \\
\hline & & n (\%) & n (\%) & n (\%) & \\
\hline ASCUS & & & & & \\
\hline & Absent & $130(96.3)$ & $84(96.6)$ & $46(95.8)$ & $0.999^{3}$ \\
\hline & Present & $5(3.7)$ & $3(3.4)$ & $2(4.2)$ & \\
\hline AGUS & & & & & \\
\hline & Absent & $132(97.8)$ & $85(97.7)$ & $47(97.9)$ & - \\
\hline & Present & $3(2.2)$ & $2(2.3)$ & $1(2.1)$ & \\
\hline LSIL & & & & & \\
\hline & Absent & $89(65.9)$ & $55(63.2)$ & $34(70.8)$ & $0.449^{4}$ \\
\hline & Present & $46(34.1)$ & $32(36.8)$ & $14(29.2)$ & \\
\hline HSIL & & & & & \\
\hline & Absent & $57(42.2)$ & $38(43.7)$ & $19(39.6)$ & $0.717^{4}$ \\
\hline & Present & $78(57.8)$ & $49(56.3)$ & $29(60.4)$ & \\
\hline SCC & & & & & \\
\hline & Absent & $134(99.3)$ & $86(98.9)$ & $48(100.0)$ & - \\
\hline & Present & $1(0.7)$ & $1(1.1)$ & $0(0.0)$ & \\
\hline ADENC & KARSIIN & & & & \\
\hline & Absent & $134(99.3)$ & $87(100.0)$ & 47 (97.9) & - \\
\hline & Present & $1(0.7)$ & $0(0.0)$ & $1(2.1)$ & \\
\hline Preop b & iyopsi & & & & \\
\hline & CIN II & $82(60.7)$ & $54(62.1)$ & $28(58.3)$ & $0.715^{4}$ \\
\hline & CIN III & $53(39.3)$ & 33 (37.9) & $20(41.7)$ & \\
\hline
\end{tabular}

${ }^{1}$ Independent Samplse T Test(Bootstrap), ${ }^{2}$ Mann Whitney U test(Monte Carlo), ${ }^{3}$ Fisher Exact Test(Exact), ${ }^{4}$ Perason Chi-Square Test(Exact), SD.:Standard deviation, Min.:Minimum, Max.:Maximum. 
Tablo 2: Farklı konizasyon tekniği uygulanan hastalarda sonuçların karşılaştırılması.

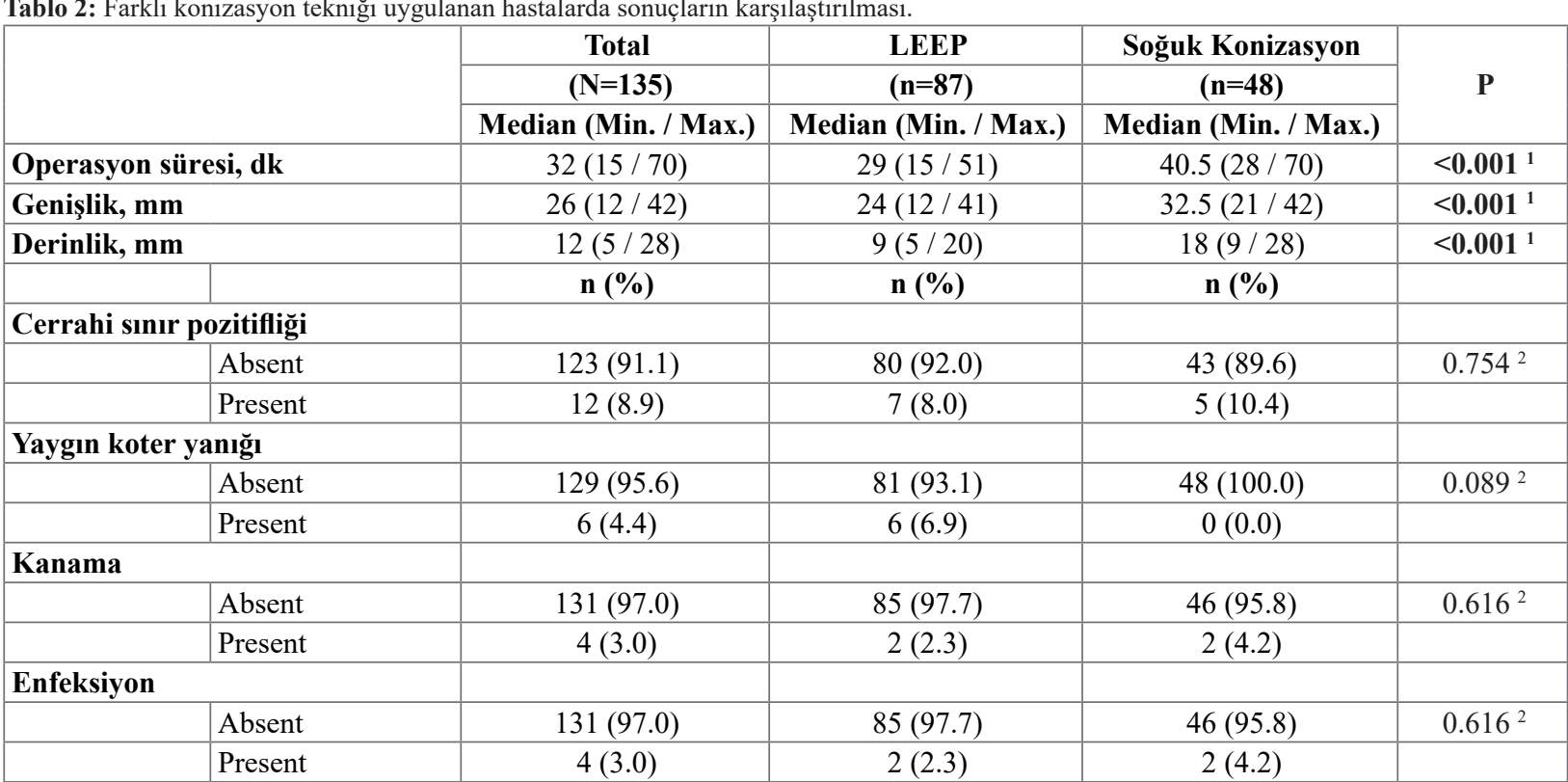

${ }^{1}$ Mann Whitney U test (Monte Carlo), ${ }^{2}$ Fisher Exact Test(Exact), Min.:Minimum, Max.:Maximum.

Tablo 3: Konizasyon materyalinin nihai histopatolojik sonuçları.

\begin{tabular}{|c|c|c|c|c|}
\hline & Total & LEEP & Soğuk Konizasyon & \multirow{2}{*}{$\mathbf{P}$} \\
\hline & $(\mathrm{N}=\mathbf{1 3 5})$ & $(n=87)$ & $(n=48)$ & \\
\hline \multicolumn{5}{|c|}{ Hastalık yok } \\
\hline Absent & $129(95.6)$ & $83(95.4)$ & $46(95.8)$ & $0.999^{1}$ \\
\hline Present & $6(4.4)$ & $4(4.6)$ & $2(4.2)$ & \\
\hline \multicolumn{5}{|c|}{ CIN } \\
\hline Absent & $17(12.6)$ & $12(13.8)$ & $5(10.4)$ & $0.974^{2}$ \\
\hline I & $11(8.1)$ & $7(8.0)$ & $4(8.3)$ & \\
\hline II & $67(49.6)$ & $43(49.4)$ & $24(50.0)$ & \\
\hline III & $40(29.6)$ & $25(28.7)$ & $15(31.3)$ & \\
\hline \multicolumn{5}{|c|}{ Karsinoma in situ } \\
\hline Absent & $127(94.1)$ & $81(93.1)$ & $46(95.8)$ & $0.711^{1}$ \\
\hline Present & $8(5.9)$ & $6(6.9)$ & $2(4.2)$ & \\
\hline \multicolumn{5}{|c|}{ Evre 1A1 Servikal kanser } \\
\hline Absent & $132(97.8)$ & $85(97.7)$ & $47(97.9)$ & - \\
\hline Present & $3(2.2)$ & $2(2.3)$ & $1(2.1)$ & \\
\hline
\end{tabular}

\footnotetext{
${ }^{1}$ Fisher Exact Test(Exact), Fisher Freeman Halton Test (Monte Carlo).
}

Kim ve arkadaşları LEEP ile konizasyon yap1lan 78 olguyu incelediklerinde 31 (\%39.7) olguda marjin pozitifliği saptamışlardır. Bunların 29'una histerektomi yapıldığında, 4 olgu invaziv adenokarsinom olmak üzere toplam 14 (\%48) olguda rezidüel hastalık saptanmıştır. Marjin negatif olgulardan 30'una ise histerektomi yapıld1ğında biri invaziv adenokarsinoma olmak üzere 5 (\%16.7) olguda rezidüel hastalık bulunmuştur. Bu durum marjin negatif olgularda da rezidüel hastalık riski bulunduğunu ve hasta takibi açısından dikkatli olunması gerektiğini göstermektedir (5). Yine Duesing ve arkadaşlarının (2012) yaptığı bir çalışmada; CIN'lerin tedavisi için yapılan LEEP uygulamasının etkinliğini değerlendirilmiştir. Toplam 266 LEEP uygulanan hasta retrospektif olarak incelenmiş, tam eksizyon \%84,3 hastada sağlanmıştır.
$\% 13,5$ vakada sınırlar güvenli bulunmamış, $\% 2,3$ hasta da ise lezyon tam olarak çıkartılamamıştır (6). Azodi ve arkadaşları toplam 40 adenokarsinoma in situ olgusunda farklı konizasyon tekniklerinin marjin pozitifliği açısından önemini araştırmışlardır. Bu çalışmanın sonuçlarına göre yazarlar soğuk konizasyon yapıldığında marjin pozitifliğinin en az oranda görüldügünü bildirmekte ve tercih edilmesi gereken konizasyon yöntemini soğuk konizasyon olması gerektiğini açıklamaktadırlar (7). Bryson ve arkadaşları ise LEEP ile tedavi edilen toplam 31 adenokarsinoma in situ ve endoservikal glandüler displazi olgusundan 7'sinde (\%22.6) marjin pozitifliği saptamışlar; daha sonra bu olgulardan 5 'ine histerektomi ve 2'sine soğuk konizasyon uygulandıklarında lezyona rastlamamışlardır. $\mathrm{Bu}$ olgular ortalama 51 ay izlendiği halde nüks etmemiştir. 
$\mathrm{Bu}$ nedenle LEEP tedavisinin güvenilir olduğunu, en azından marjin negatif saptanan olgularin ikinci tedavi değerlendirilmesine gerek olmadığını ileri sürmektedir (8).

LEEP histopatolojik tanı olanağı sağlayan, çabuk öğrenilebilen, cihaz ve sarf maliyeti düşük bir teknik olup soğuk konizasyona göre daha pratik bir işlemdir. Çalışmamızda LEEP yapılan hasta grubunda operasyon süresini soğuk konizasyon grubuna göre anlamlı olarak daha kısa bulduk. Soğuk konizasyon klinik olarak servikal kanser açısından yüksek riskli durumlarda, endoservikal kanala uzanım gösteren vakalarda ve transformasyon zonunun inverte olduğu durumlarda klinisyenler tarafından öncelikli tercih sebebi olmaktadır. Yine soğuk konizasyon genellikle ailesini tamamlamıș ve fertilite beklentisi olmayanlarda LEEP'e göre daha çok tercih edilmektedir. Çoğunlukla multipar olan bu hastalarda transformasyon zonunun daha dişta yer almasına bağlı olarak spesimenin derinliği ve genişliği daha fazla olmaktadır. Biz de çalışmamızda soğuk konizasyon grubundaki hastalarda gravida, parite ile spesimenin derinliği ve genişliği parametrelerini LEEP grubuna göre anlamlı olarak yüksek bulduk.

Skuamöz intraepitelyal neoplazilerde tedavinin amacı transformasyon zonunu eradike etmektir. Transformasyon zonunun kesin lokalizasyonu ve görülebilirliği optimal tedavide, tedavi kaynaklı morbiditede en önemli belirleyicidir. LEEP veya soğuk konizasyonun en önemli komplikasyonlarından birisi de serviksten fazla miktarda doku ç1karılmasıdır. $\mathrm{Bu}$ uygulamaların özellikle genç ve doğurmamış hastalarda gelişebilecek servikal yetersizlik nedeniyle düşük oranlarında artışlara yol açabileceğinden uygun endikasyonlarda ve uygun teknikle yapılması önem taşır. Başta kanama ve servikal yetersizlik olmak üzere ciddi komplikasyonlar ortaya çıkabilir. Çalıșmamızda LEEP veya soğuk konizasyon işlemi sırasında gerekli durumlarda hemostaz koterizasyon, sütürasyon veya monsel's solüsyonu ile sağlandı ancak postoperatif gözlem sirasinda LEEP grubunda 2 hastada (\%2.3), soğuk konizasyon grubunda da $2(\% 4.2)$ hastada vajinal kanama izlendi ve gruplar arasinda postoperatif kanama oranı açısından fark izlenmedi. Aynı şekilde postoperatif ilk bir aylık sürede ortaya çıkan genital enfeksiyon oranları açısından da farklılık izlenmedi. Değişik tedavi seçeneklerinin etkinlik ve morbiditelerinin değerlendirildiği çalışmalar genel olarak kontrol grubu içermeyen gözlemsel çalışmalar olup hasta seçim ve takibinde değişken kriterler kullanıldığı için tedavi sonuçlarını yorumlama konusunda güçlükler oluşmaktadır. Tedavi modalitelerinin etkinlik ve morbiditesinin kapsamlı değerlendirmesi Martin-Hirsch ve ark. tarafindan 2009'da yayımlanan Cochrane Kütüphanesi derlemesidir (9). Sonuç olarak bu 29 randomize kontrollü çalışmada maliyet ve morbidite gözetildiğinde hiçbir tekniğin üstünlüğü gösterilememiştir.

Çalışmamızda LEEP ve soğuk konizasyon yapılan hasta gruplarında gerek preoperatif sitoloji sonuçları gerekse de kolposkopik biyopsi sonuçlar1 analiz edildiğinde tanı grupları açısından oranlar benzer bulundu. Yüksek dereceli intraepitelyal neoplazi tanısıyla LEEP veya soğuk konizasyon yaptı̆̆ımız hastaların postoperatif nihai patoloji sonuçları incelendiğinde de tanı grupları açısından istatistiksel olarak anlaml fark bulunmadi. Servikal intraepitelyal neoplazi endikasyonu ile yapılan LEEP sonrasında negatif sonuçlar da raporlanmaktadir. HSIL nedeniyle LEEP yapılan olgularda negatif çıkma oranlarını \%14 ile \%17 arasında bildiren çalışmalar bulunmakla birlikte (10). Witt ve arkadaşlarının (2012) HSIL tanısı ile LEEP uyguladıkları 378 hastada \%24 oranında negatif bulgular veya LGSIL sonucuna ulaşılmıştır. Çalışma sonucunda ise negatif ve pozitif LEEP sonuçlarının takiplerinin aynı şekilde yapılması önerilmiştir (11).

Tedavi başarısı olarak 'cerrahi sınırlarda lezyon izlenmemesi' alındığında yüksek dereceli servikal intraepitelyal neoplazilerin tedavisi için yapılan LEEP ve soğuk konizasyon tekniğinin başarı ve etkinliği benzer bulunmuştur. Erken dönem komplikasyonları da benzer olmakla birlikte LEEP tekniğinde soğuk konizasyona göre operasyon süresi daha kısa bulunmuştur. Soğuk konizasyon tekniğinde ise termal hasar olmaması ve histopatolojik değerlendirme için LEEP'e göre daha fazla miktarda doku sağlanabilmesi avantajlı olduğu yönleridir.

\section{KAYNAKLAR}

1. Wright TC, Massad LS, Dunton CJ, Spitzer M, Wilkinson EJ, Solomon D. 2006 consensus guidelines fort he management of women with cervical intraepithelial neoplasia or adenocarcinoma in situ. Am J Obstet Gynecol 2007;340-45.

2. Mitchell MF, Tortolero-Luna G, Wright T, Sarkar A, Richar$d s$-Kortum R, Hong WK. Cervical human papillomavirus infection and intraepithelial neoplasia: a review. J Natl Cancer Inst Monogr 1996;21:17-25.

3. Prendiville W., J. Cullimore, and S. Norman. Large loop excision of the transformation zone (LLETZ). A new method of management for women with cervical intraepithelial neoplasia. Br. J Obstet Gynaecol, 1989. 96(9):1054-60.

4. Arbyn M., Perinatal mortality and other severe adverse pregnancy outcomes associated with tretment of cervical intraepithelial neoplasia: meta-analysis. BMJ, 2008, 337.

5. Kim JH, ParkJY, Kim DY. The role of loop electrosurgical excisional procedure in the management of adenocarcinoma in situ of the uterine cervix. Eur J Obstet Gynecol Repr Biol 145:100-103, 2009.

6. Duesing N, Schwarz J, Choschzick M, Jaenicke F, Gieseking $F$, Issa $R$, et al. Assessment of cervical intraepithelial neoplasia (CIN) with colposcopic biopsy and effi cacy of loop electrosurgical excision procedure (LEEP). Arch Gynecol Obstet. 2012;286(6):1549-54.

7. Azodi M, Chambers SK, Rutherford TJ. Adenocarcinoma in situ of the cervix: Management and outcome. Gynecol Oncol 73:348353,1999 .

8. Bryson P, Stulberg R, Shepherd L. Is electrosurgical loop excision with negative margins sufficient treatment for cervical ACIS? Gynecol Oncol 93:465-468,2004.

9. Martin-Hirsch. Surgery for cervical intraepithelial neoplasia. Cochrane Database Sys Rev, 2010.6:p CD001318.

10. Diakomanolis E, Haidopoulos D, Chatzipapas I, Rodolakis A, Stefanidis K, Markaki S. Negative cone biopsies: a reappraisal [erratum in J Reprod Med. 2003;48(10):833]. J Reprod Med. 2003;48(8):617-621.

11. Witt BL, Factor RE, Jarboe EA, Layfi eld LJ. Negative loop electrosurgical cone biopsy finding following a biopsy diagnosis of high-grade squamous intraepithelial lesion: frequency and clinical significance. Arch Pathol Lab Med. 2012;136(10):1259-61. 